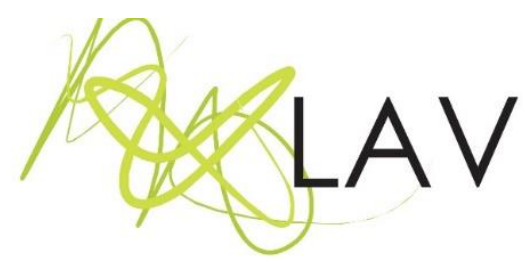

\title{
Estágio Docente, Desenho e Símbolo: tríade para investigar e compreender corporeidades afro-brasileiras
}

Teaching Internship, Design and Symbol: triad to investigate and understand AfroBrazilian corporeities

Eduardo Oliveira Miranda ${ }^{\mathbf{i}}$

Universidade Federal da Bahia

\section{Resumo}

O texto apresenta uma experiência docente articulada durante a travessia do autor pelo programa de pós-graduação em Desenho, Cultura e Interatividade -UEFS, precisamente no componente curricular Estágio Docente (PIMENTA, 2011), no qual assumiu a regência de uma turma de Desenho Artístico ofertada como atividade optativa para turmas de graduação. Nesse cenário, trabalhou-se com a categorias Desenho (FERREIRA, 2005, 2007; GOMES, 1996), Imagem e Símbolo (MORIN, $1975,1999)$ com a prerrogativa de compreender a realidade dos educandos a partir da projeção gráfica e como eles podem explicar as suas intersubjetividades através dos traços e linhas. Nesse cenário, criaram-se desenhos elucidativos das populações negras o que proporcionou as discussões sobre as corporeidades afrobrasileiras. Em relação a metodologia, optamos pela perspectiva fenomenológica ao enfocar a utilização de imagens na Etnopesquisa Crítica (MACEDO, 2010). Portanto, o estágio docente passou a ser compreendido como uma experiência rica para a validação da práxis educativa ao passo que o mesmo pode oportunizar as mutabilidades identitárias (HALL, 2006).

Palavras-chave: Estágio docente, Desenho, Símbolo.

\section{Abstract}

The text presents a teaching experience articulated during the crossing of the author by the post-graduation program in Drawing, Culture and Interactivity -UEFS, precisely in the curricular component Teaching Internship (PIMENTA, 2011), in which he assumed the regency of a group of Artistic Design offered as an optional activity for undergraduate classes. In this scenario, we worked with the categories Drawing (FERREIRA, 2005, 2007; GOMES, 1996), Image and Symbol (MORIN, $1975,1999)$ with the prerogative to understand the reality of learners from the graphic projection and how they can explain its intersubjectivities through the strokes and lines. In this scenario, it was created an illustrative drawing of the black populations that provided the discussions about Afro-Brazilian corporations. Therefore, the teaching stage came to be understood as a rich experience for the validation of the educational praxis, while the same can offer the identity mutabilities (HALL, 2006).

Key words: Teaching stage, Drawing, Symbol. 


\section{Desenhos iniciais}

"Quando não souberes para onde ir, olha para trás e saiba pelo menos de onde vens".

(Provérbio Africano)

Iniciar as reflexões com as colocações do provérbio africano elucida o potencial que as nossas histórias abarcam no trato com a identidade que apresentamos no momento presente. Refletir sobre as questões que forjam o nosso atual corpo é de suma relevância no âmbito da profissionalização docente, o qual, pode ter o início nos cursos de licenciaturas e continuar a se constituir no decorrer das múltiplas trajetórias de vidas.

Nisso, verificamos a direta associação do componente Estágio Docente aos momentos de formação inicial nas licenciaturas. Contudo, não podemos silenciar as formações das identidades docentes oportunizadas na pós-graduação stricto sensu, pois para muitos mestrandos e mestrandas se configura como a primeira oportunidade de efetivar a práxis educativa em turmas de Nível Superior.

Sendo assim, o estágio configura-se como um conjunto de atividades de aprendizado social, cultural, político, profissional, momento de aproximação com o espaço no qual futuros mestres terão a oportunidade para desenvolver práticas de ensino. Destarte, é no estágio que reconhecemos as realidades educacionais, as dificuldades, desafios e possibilidades que o ambiente acadêmico abarca. Dessa forma, apresentaremos um relato de experiência articulado no período em que estive na condição de aluno do Programa de Pós-Graduação em Desenho, Cultura e Interatividade - PPGDCI da Universidade Estadual de Feira de Santana - UEFS, unidade localizada no semiárido baiano.

Se ater a esse período da minha formação profissional e pessoal é compreendido aqui como um convite para vislumbrar que refletir sobre a prática "leva à (re)construção de saberes, atenua a separação entre teoria e prática e assenta na construção de uma circularidade em que a teoria ilumina a prática e a prática questiona a teoria" (ALARCÃO, 2005, p. 99). Soma-se a isso, a questão de que o estágio, assim como qualquer momento das nossas vidas, oportuniza rupturas e continuidades, onde a "identidade torna-se uma 'celebração móvel': formada e transformada continuamente em relação às formas pelas quais somos 
representados ou interpelados nos sistemas culturais que nos rodeiam" (HALL, 2006, p. 12).

Ao estagiário faz-se necessário o olhar observador, investigativo e reflexivo que aproveite minúcias do cotidiano para pensar a prática de ensino de uma forma mais ampla, onde a autorreflexão deve ser constante. Partindo do pressuposto de que a formação dos professores deve ser continuada, entendo que a reflexão sobre a própria prática é um elemento relevante no processo engenhoso que infere na construção da identidade docente, nas escolhas metodológicas, políticas e éticas as quais são de suma importância para o professor:

[...] na formação permanente dos professores, o momento fundamental é o da reflexão crítica sobre a prática. É pensando criticamente a prática de hoje ou de ontem que se pode melhorar a próxima prática. O próprio discurso teórico, necessário à reflexão crítica, tem de ser de tal modo concreto que quase se confunda com a prática (FREIRE, 1998, p. 44).

O estágio é um momento único na prática docente, visto que se percebe, de fato, a efetivação da práxis, ou seja, o encontro entre a teoria e a prática. Ao passo em que o estagiário se reconhece como futuro professor e, porque não dizer, como responsável no momento de vigência do estágio pela mediação na construção de conhecimento dos alunos, sua ação pedagógica é favorecida por meio da reflexão acerca do compromisso com a aprendizagem significativa, o desenvolvimento e execução de projetos de ensino, o uso de conteúdos interdisciplinares, novos métodos avaliativos e metodologias.

A intervenção aqui explanada apresenta uma proposta de ensino desenvolvida como pré-requisito da disciplina Estágio Docência e que teve a sua aplicabilidade no componente curricular optativo Desenho Artístico ofertada pelo Departamento de Letras e Artes da Universidade Estadual de Feira de Santana - UEFS. Encontramos uma turma mista com a predominância de discentes oriundos da Licenciatura em Matemática, sobretudo do $5^{\circ}$ semestre.

A escolha da disciplina Desenho Artístico se justifica pelo fato da ementa dispor de bases de informações que reverberam na construção do conhecimento acerca da categoria de análise Desenho. Além disso, o espaço educativo apresentou elementos fundantes na tessitura da minha dissertação, posto que a metodologia explicitada no plano de curso teve respaldo no simbólico e na visualidade, sendo que ambas compõem a hermenêutica que fundamentaram a pesquisa de mestrado. 
Para alcançar a proposta de intervenção escolhemos o conteúdo O Desenho como manifestação criativa. Em relação a nossa metodologia, recorremos a perspectiva fenomenológico por perceber que a mesma nos ajuda a descrever para compreender um determinado fenômeno, no nosso caso, as experiências desencadeadas no estágio docente. Dentro dessa visão de pesquisa, optamos pela Etnopesquisa Crítica elucidada pelo pesquisador Roberto Macedo (2010), para o qual o sujeito de estudo tem total participação na produção dos dados, bem como na suas interpretações, pois "traz pelas vias de uma tensa interpretação dialógica e dialética a voz do ator social para o corpus empírico analisado e para a própria composição conclusiva do estudo" (MACEDO, 2010, p. 10). Ainda nesta abordagem, Macedo evidencia a utilização das imagens como dispositivo metodológico para a produção dos dados, posto que:

Apreendem-se formas, volumes, cores, movimentos, que adquirem, num primeiro momento, estruturas frásicas e significantes, mas que compõem, em um segundo, flashes de concretização semântica. O flash semântico, o instantâneo do significado, substitui a lógica do significado verbal (MACEDO, 2010, p. 125).

Portanto, a aplicabilidade dos desenhos durante o estágio docente buscou acessar significados que nem sempre são exposto no ato verbal. A partir disso, traçamos o objetivo geral: Proporcionar que os sujeitos envolvidos na prática pedagógica compreendam que o desenho é concebido inicialmente no plano mental e que dessa forma os elementos simbólicos que constituem o seu gosto musical podem ser representados graficamente. Em seguida, criamos: Específico: Desenhar os três territórios que compõem o circuito da micareta de Feira de Santana; Representar graficamente no papel, com auxílio do lápis preto, 1 elemento simbólico relevante para eles e que tenha relação com um dos estilos musicais apresentados no vídeo; Construir em coletivo um painel no qual estejam representados graficamente os elementos simbólicos dos estilos musicais que remetem a Micareta de Feira de Santana.

Então, para desencadear o movimento textual que estamos compondo neste relato sentimos a necessidade de evidenciar à luz da teoria científica como compreendemos algumas categorias centrais acessadas durante a intervenção pedagógica. Portanto, a seguir faremos um levantamento acerca dos conceitos: Símbolo e Desenho. A escolha dessas duas categorias não se deu de forma aleatória, muito pelo contrário, ambas foram elencadas por serem potentes no ator 
de expor subjetividades, emoções, conhecimentos, entre tantas outras particularidades que compõem os nossos corpos-territórios "que para onde se desloca carrega consigo toda a bagagem cultural construída ao longo das suas trajetórias" (MIRANDA, 2014, p. 69-70).

\section{Simbolismo: o Mítico, o Simbólico e o Mágico}

A consciência da imagem modificou a visão que os nossos ancestrais, neandertais, concebiam acerca da sua própria existência. A percepção do duplo através do reflexo da autoimagem na água ou em pedras polidas proporcionou uma relação diferenciada com a sua espiritualidade.

Diversos estudos apontavam que a origem do homem sapiens estava atrelada a fatores que variavam desde a organização em sociedade e/ou desenvolvimento da fala. No entanto, a sepultura e as pinturas se caracterizam como marcos que fundamentam a origem dos primeiros homens dotados de estruturas cognitivas mais complexas. Essa nova forma de encarar o mundo representou "uma irrupção da morte na vida humana, mas também modificações antropológicas que permitiram e provocaram essa irrupção" (MORIN, 1975, p. 102).

Edgar Morin (1999), compreende que o envolvimento dos nossos ancestrais com a morte está articulado ao modo de conhecimento simbólico/mitológico/mágico. Para explicar esse modo de pensar o autor divide a análise em símbolo, mito e magia. Vamos nos ater ao entendimento do termo símbolo, sobretudo na visão de Cassirer apud Moura (2000), Morin (1999) e Araújo (2008).

No texto "O simbólico em Cassirer" a filósofa Moura (2000) aponta que o símbolo serve para designar criações humanas que variam de acordo com as experiências de cada grupo social e os seus respectivos indivíduos. Sendo assim, a religião, a arte, a linguagem e a história são criações humanas dotadas de símbolos relevantes para determinadas culturas.

Nesse prisma, Cassirer apud Moura (2000, p. 76) defende que "deveríamos definir o homem como animal symbolicum e não rationale". O pensamento racional analítico não consegue compreender as contradições que fazem parte da humanidade, posto que "a vida e a cultura humana, na radicalidade de suas formas expressivas, são tecidas pela trama da heterogeneidade, das contradições e das ambiguidades que são irredutíveis aos modelos fundados na homogeneização" (ARAÚJO, 2008, p. 107). Ou seja, a multiplicidade que caracteriza a existência 
humana não se reduz ao pensamento racional que essencialmente percebe o outro de forma universalizante. Nesse movimento, o outro é percebido como diferente, inadequado de acordo com os valores que tecem a visão dos indivíduos que compõem as civilizações nas quais o pensamento técnico/empírico predomina de forma homogeneizadora.

Ainda com fundamentação em Cassirer entendemos que os símbolos carregam sentidos que viabilizam as interlocuções entre as coisas do mundo e o espírito. Outra característica do símbolo está na sua etimologia, a qual conota a ideia de ligação e reunião. O poder de reunir permite a conjugação do visível com o invisível e "entrelaça e religa os polos e as instâncias diversas dos fenômenos" (ARAúJO, 2008, p. 109).

Nesse viés de compreensão, todo símbolo deve ser entendido como luz e sombra, numa linguagem típica do pensamento duplo, o qual tece uma interpretação que varia de acordo a identidade que simboliza. Esta relação íntima com cada grupo social estabelece sentidos que independe de explicação científica racional analítica: "o símbolo não se explica; nos implica com a in-tensidade e a complexidade dos fenômenos do existir nos levando a senti-los e a compreendê-los, encharcados em seu vigor seminal, em suas dimensões anímicas" (ARAÚJO, 2008, p. 111).

Em consonância com Cassirer, Morin (1999) intenta estabelecer cinco características que correspondem aos símbolos: 1) o símbolo admite uma identificação com o seu referencial materializado; 2) o símbolo materializado tem o poder de evocar uma série de significados; 3) O símbolo congrega um coagulom de sentidos que representam uma infinidade de significações; 4) O símbolo não depende do pensamento racional/empírico para existir e ser significativo; 5) 0 símbolo tem significado para a cultura no qual foi instaurado. Os pontos elencados por Morin evidenciam a dualidade presente no espírito humano e no ethos que reverberam sua identidade, bem como seus valores, mitos, sentidos e crenças. Aqui, percebemos a importância da tradição e sua dinamicidade no desenhar da vivência do sujeito enquanto ser inventivo de: religião, arte, história e linguagem.

Dessa forma, concebemos que é através das variações e descobertas acarretadas pelas experiências humanas que o símbolo continua a existir. Ele não deve ser encarado como uma estrutura fixa, visto que a flexibilidade faz parte da sua origem, bem como da sua reprodução. O símbolo deve ser encarado como um elemento constitutivo do espírito humano, carregado de complexidades, valores, 
sentidos, crenças e percepções e que extrapola o entendimento do pensamento empírico/técnico/racional.

\section{Desenho e Imagem como aportes evocadores de Símbolos}

A díade conceitual aqui elencada não se desvela de forma amiúde ao contexto temático do presente texto. Embora cada um possua expressividade e consistência teórica particular, os conceitos de Desenho e Imagem estabelecem conexão direta entre si, tendo em vista o conjunto de atributos que Ihes conferem sentido e significado. Araújo (2008) assevera que as formas expressivas (imagens, desenhos, pinturas) e seus símbolos constituem-se enquanto elos entre os fenômenos e o imaginário dos sujeitos. Ou seja, tais conceitos não somente entrelaçam-se, como são bases representativas do pensamento simbólico.

A categoria Desenho enseja uma breve ilustração posto a sua dimensão epistemológica. Para tanto, inicialmente recorremos ao dicionário Aurélio a fim de estatuir denotativamente o conceito supracitado. Segundo o dicionário, desenho refere-se ao resulto do ato ou ação de desenhar, representar sobre uma superfície formas e/ou um tema real ou imaginário. Em seguida, o verbo desenhar é designado como descrever, representar, projetar.

Entendemos, pois, o desenho enquanto concepção mental que nasce, é pensado, configurado e, por conseguinte projetado. Portanto, o pensar também se constitui enquanto desenho. Nesse prisma, faz-se oportuno elucidar que para além da ação, do concretamente esboçado no papel e tido enquanto arte ou qualquer outra coisa que o valha, o desenho tem em seu cerne o caráter inerente de comunicar haja vista o intento de quem desenha.

Gomes (1996, p. 13), entende tal categoria como "uma das formas de expressão humana que melhor permite a representação das coisas concretas e abstratas que compõem o mundo natural ou artificial em que vivemos". Ainda nesse prisma, Ferreira (2007) afirma que o desenho vem a ser um sistema de signos ou sinais que comunicam, expressam valores, ideias, significados, sentidos. Ou seja, por meio do desenho é possível representar, comunicar, o que o torna substancialmente uma linguagem que contém elementos que não se limitam ao concretamente visível e que, necessariamente diligenciam interpretação. É, talvez, nesse contexto que o pensar sobre o desenho caminha em paralelo com a imagética. 


\section{Ciclos da experiência: como aconteceu a intervenção}

O estágio é uma etapa fundamental na construção do conhecimento pedagógico e da identificação ou não do profissional com o seu campo de atuação. Durante a observação tem-se a oportunidade de analisar a prática de um professor regente com a titulação de doutor e com vasta experiência profissional, o que possibilita um auxílio, o trajeto de construção das nossas escolhas enquanto futuros profissionais do ensino superior.

O ato de ser professor está em constantes transformações, pois a pós-modernidade exige dos educadores a inserção de temas, pouco debatidos, na construção da identidade docente, por exemplo, o multiculturalismo:

Uma vez apto a enfrentar tais situações, esses professores tendem a compreender, respeitar e valorizar as diferentes culturas de seus alunos fazendo com que as mesmas sejam ponto de partida para o seu fazer pedagógico cotidiano. (ARBACHE, 2000, p. 46).

Mais uma vez percebe-se a importância do educador no processo de valorização sobre o conhecimento que os alunos trazem para a sala de aula. Para que o processo sócio construtivista seja eficiente, faz-se necessário que o professor indique atividades que proporcionem as trocas de vivência e de acordo com cada fala, retire temas geradores, os quais devem ser debatidos com a finalidade de modificar a prática social do grupo.

Durante o estágio tive a oportunidade de observar/analisar quatro aulas. Em tese, trata-se de uma atividade fácil, já que necessita apenas aguçar o olhar crítico de observador e tecer ideias acerca da aula, da postura do professor, da dinâmica da sala de aula e afins. Contudo, ao ver na figura do regente a responsabilidade pedagógica e profissional de quem deve mediar uma sala de aula no nível superior, notei que não seria tão fácil somente observar, posto que o docente responsável pela turma apresenta uma didática e metodologia que foge do tradicionalismo reproduzido em boa parte das aulas da graduação. Aproveito para frisar que tal constatação também teve respaldo nos relatos de todos os graduandos do referido semestre.

A primeira observação apresentou um caráter tímido. O professor regente me recepcionou e apresentou à turma. No meu imaginário estava programado que deveria ter uma postura que pouco fosse percebida pelos demais sujeitos presentes naquele espaço. No entanto, o convite para participar das construções me surpreendeu. A atividade proposta pelo docente consistia em desenhar uma 
composição que continha algumas frutas. Inicialmente relutei, mas em seguida aceitei o desafio e comecei a rabiscar. Percebi que aquela aula não obedecia a um cronograma pré-estabelecido, posto que as dúvidas, bem como as dificuldades dos educandos é que serviam de temas geradores a serem trabalhados em coletivo. No final do encontro consegui apresentar um desenho com aspectos infantis, visto que não tenho o hábito de praticar a projeção gráfica.

$\mathrm{Na}$ segunda aula estava ansioso para saber qual seria o próximo desenho de observação. Então, o professor solicitou que desenhássemos, a partir da observação, uma flor. Os traços de uma flor são extremamente delicados. Apresentei imensa dificuldade para projetar no papel. No entanto, observei que tais dificuldades é que aproximava os discentes do docente. Nesse movimento, tive a oportunidade de me aproximar dos educandos e trocar experiências, desejos, angústias, dentre tantos outros elementos que compõem as identidades de cada sujeito.

A terceira observação continuou com o desenho da flor. Fomos conduzidos a realizar uma projeção que se aproximasse do real. Mais uma vez deparei-me com a dificuldade em desenhar. Porém, risquei, apaguei, risquei novamente até conseguir um desenho. O interessante do desenho de observação é que mesmo projetando um objeto cada indivíduo desenha com os traços peculiares ao seu olhar. Ainda nesse encontro, nos foi proposto a projeção de um banco, o que aparentemente seria uma tarefa fácil, no entanto os traços perpendiculares exigem imensa concentração e habilidade com a dimensão.

$\mathrm{Na}$ quarta e última observação o professor regente ensinou no quadro como desenhar um rosto humano. Para tal projeção existem algumas técnicas indispensáveis. Tal momento caracterizou a única vez que presenciei o docente utilizando o quadro como recurso. Em todas as outras oportunidades o ensino ocorreu com ajuda do lápis preto e o papel branco.

Após esses quatro encontros, chegou o dia de assumir a turma e apresentar uma proposta um pouco diferente daquela que vinha sendo abordada em sala. De início, realizei a explanação do que venha a ser o conceito de Desenho abordado na minha dissertação. Nesse tecer apresentei o texto de Ferreira (2007) para o qual desenho deve ser encarado como algo que nasce do campo do imaginário, plano mental, e posteriormente pode ser projetado com ação manual ou com a ajuda de máquinas. Ao findar essa explanação exibi um vídeo contendo algumas fotografias da micareta 
de Feira de Santana e músicas que representasse cada um dos contextos demonstrados. O vídeo apresentou dois blocos, sendo o primeiro com imagens do circuito principal, onde desfila os blocos de trio com os artistas de renome nacional, sobretudo do Axé Music. O outro bloco organizado com imagens e músicas que continham elementos da cultura africana e afro-brasileira. Ao produzir a película tive a certeza que o primeiro bloco iria sensibilizar muito mais os jovens educandos. Para a minha surpresa, atribuíram a maior relevância aos blocos afro e afoxés. Ao questionar os educandos, obtive a seguinte resposta de uma das alunas: "O batuque dos tambores fala mais alto. A cultura negra corre pelo nosso sangue". A narrativa da educando intensifica a nossa intencionalidade metodológica, posto que permite que o sujeito responsável pela projeção gráfica sinta-se convidado a dissertar sobre os traços desenhísticos. Com isso, legitimamos a relevância do desenho como um dispositivo eficaz na exposição das questões identitárias.

Como atividade da aula, solicitei aos alunos que projetassem no painel os elementos mais significativos (Fig. 1), aqueles que apresentassem maior relevância e simbolismo com a sua realidade, ou seja, como afirma Ferreira (2007) o desenho oportuniza a grafia das ideias que circulam no campo do imaginário. O painel final apresentou desenhos extremamente coloridos e sobressaíram os símbolos da cultura afro-brasileira.

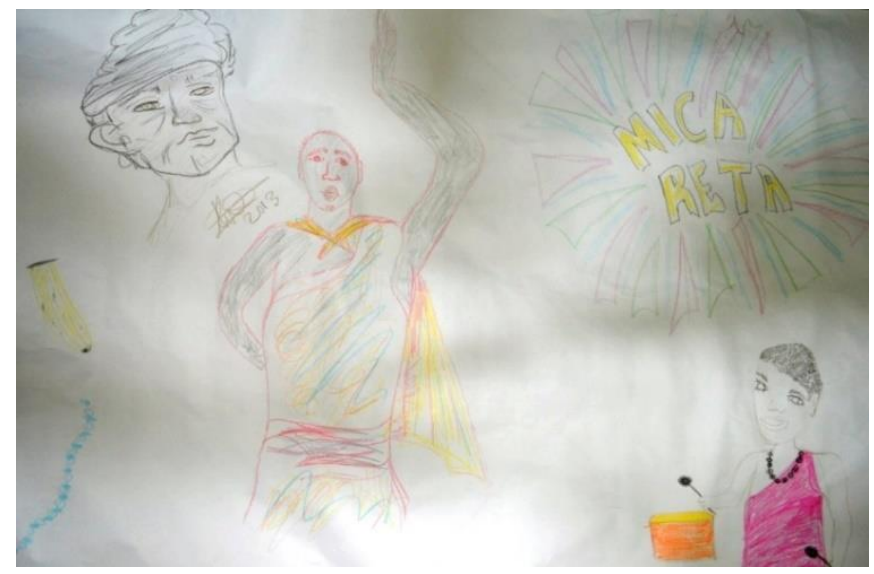

Figura.01: Painel com desenhos simbólicos.

Fonte: Elaborado pelos discentes do componente curricular Desenho Artístico $-2014$.

Nesse mosaico de cores e formas, a turma entrou em acordo e decidiram discutir acerca de duas imagens que na perspectiva deles dialogava com o recorte afrobrasileiro do vídeo, bem como, trazia para o âmbito das nossas discussões um outro olhar perante as corporeidades negras. Destarte, a (Fig. 2) "apresenta a face 
de uma mulata"1 ${ }^{1}$ que de acordo com o responsável pelo traçado está caracterizada com a estética das Mães de Santo, ou seja, as senhoras responsáveis pelas resistências dos terreiros de Candomblé.

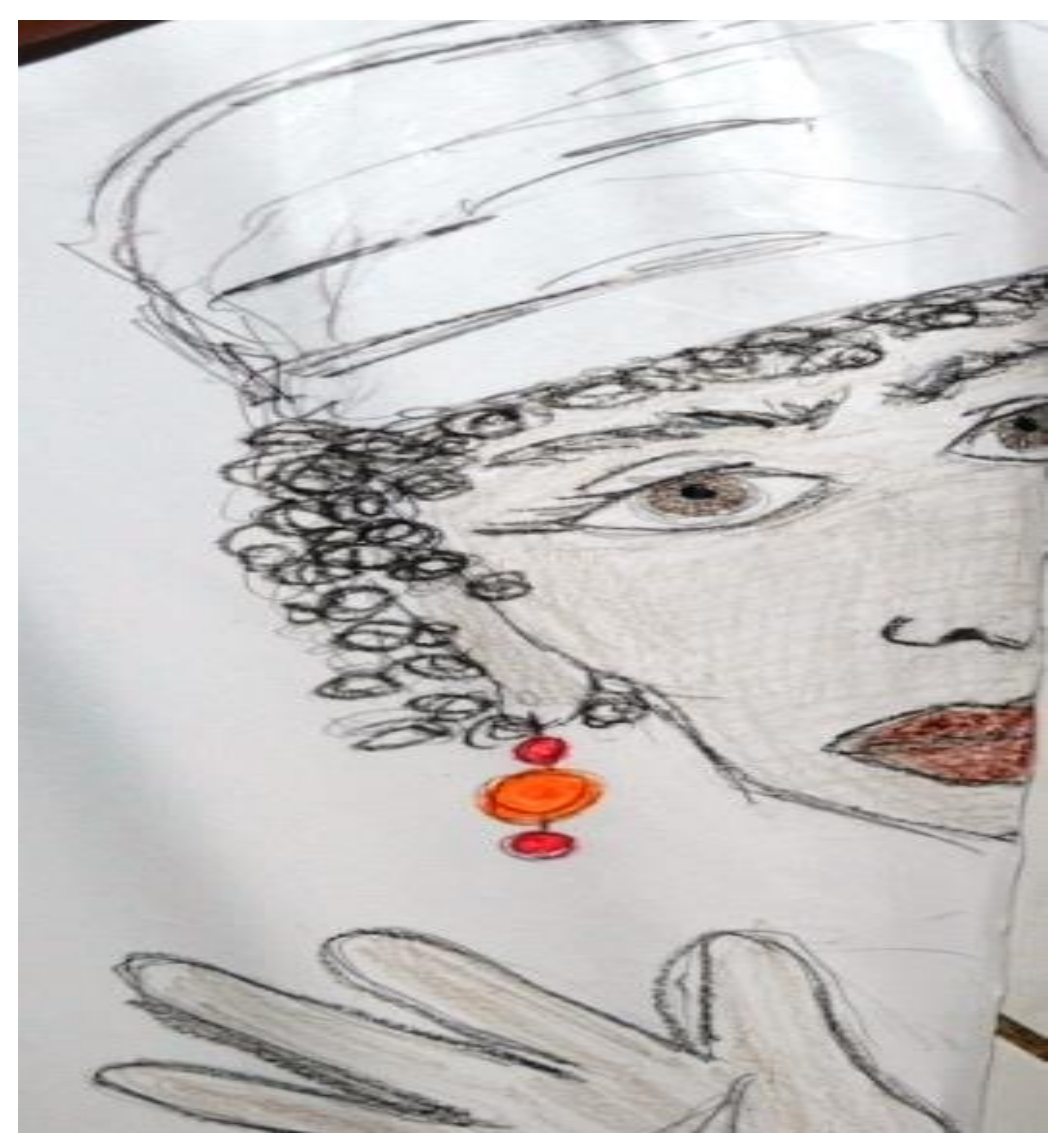

Figura.02: Mulher Negra/Mulata.

Fonte: Elaborado pelos discentes do componente curricular Desenho Artístico - 2014.

A referida projeção desenhística intensificou os nossos diálogos o que me levou a tensionar o significado histórico do termo mulata. Para os envoltos no processo de ensino-aprendizagem a utilização da nomenclatura mulata representava o processo de miscigenação da população brasileira com destaque para a beleza corporal da mulher negra. A partir disso, elucidei a problemática exposta por Munanga (2008) o qual infere:

O Brasil escravocrata herdou de Portugal a sua estrutura patriarcal de família, cujo preço foi pago pela mulher negra. O desequilíbrio demográfico entre os sexos durante a escravidão, na proporção de uma mulher para cinco homens,

\footnotetext{
${ }^{1}$ Fala do educando responsável pela projeção gráfica.
} 
conjugado com a relação assimétrica entre escravos e senhores, levou os últimos a um monopólio sexual das poucas mulheres existentes. Nesse contexto, as escravas negras, vítimas fáceis, vulneráveis a qualquer agressão sexual do senhor branco, foram, em sua maioria, transformadas em prostitutas como meios de renda e impedidas de estabelecer qualquer estrutura familiar estável. É absurdo apresentar o mulato que, na sua origem, é o fruto desse covarde cruzamento de sangue, como prova de abertura e saúde das relações raciais no Brasil. Ele evoca o ditado popular 'branca pra casar, negra pra trabalhar, mulata pra fornicar', para apoiar a ideia geral de que a mulher negra foi prostituída. Já que a existência da mulata significa o produto do prévio estupro da mulher africana, a implicação está em que, após a brutal violação, a mulata tornou-se só objeto de fornicação, enquanto a mulher negra continuou relegada à sua função original, ou seja, o trabalho compulsório. Exploração econômica e lucro definem, ainda outra vez, seu papel social (MUNANGA, 2008, p.86).

Portanto, repensar as terminologias empregadas aos corpos negros frutificou outros olhares sobre o que nos impõe a historiografia oficial, bem como, traçarmos um compromisso de dilatar os nossos conhecimentos sobre questões de etnia e raça. Aliado a isso, a professora Narcimária Luz (2000) afirma que as populações negras do Brasil devem se ater a investigar a história e cultura dos seus ancestrais, pois:

[...] consideramos importante de descendência africana adquira um conhecimento reflexivo sobre si mesma, não só para distinguir e assumir plenamente a sua originalidade, sua riqueza étnico-cultural, mas para permitir um exame analítico de sua situação, de seu destino na sociedade envolvente, para poder participar ativamente na condução desse destino, considerando seu próprio enfoque, experiência, concepções e interesses (LUZ, 2000, p. 30).

Ainda no campo das corporeidades, um dos discentes desenhou um homem negro com o instrumento de percussão ao lado (Fig. 3). Podemos visualizar um indivíduo sorridente ao realizar $\mathrm{o}$ ato de produzir sonoridades ao manusear o instrumento musical. 


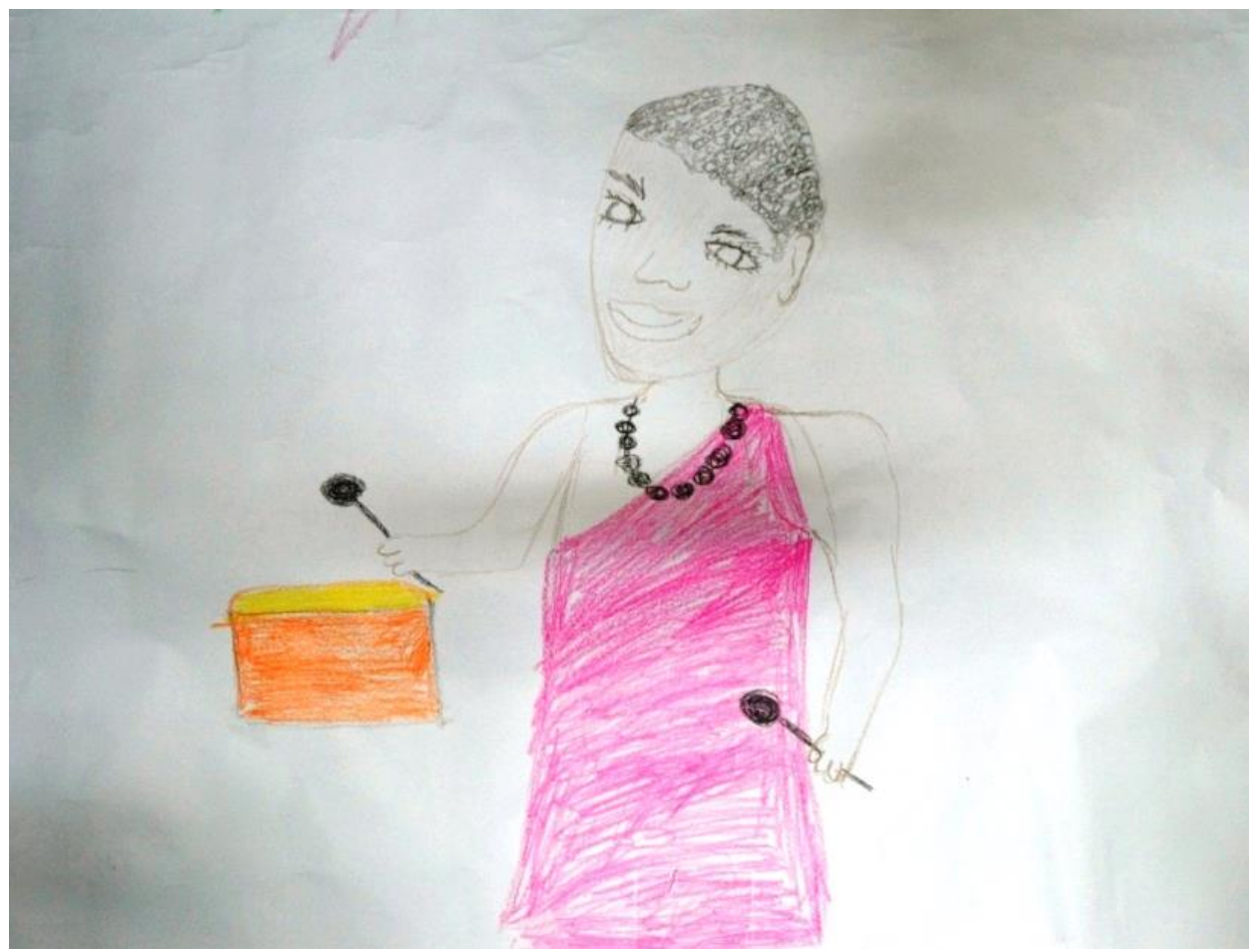

Figura.03: Percursionista.

Fonte: Elaborado pelos discentes do componente curricular Desenho Artístico - 2014.

Ao falar sobre a composição gráfica projetada no papel, o educando expressou imensa satisfação por ter tido a oportunidade de acessar as suas memórias e relembrar um período da sua vida no qual participou de um grupo de percursionistas no bairro que reside. Porém, apesar de muito envolvimento, teve que se afastar das atividades musicais por conta das demandas da universidade, assim como, pela necessidade de trabalhar para se manter na graduação. Nesse viés, voltamos mais uma vez a trazer as contribuições de Narcimária Luz (2000), ao afirmar:

Ergue-se, aí, uma pedagogia do embranquecimento que, mediante a comunicação escrita, exigirá um corpo adaptado aos valores ocidentais e submisso a uma disciplina incessante, individualizando-o, docilizando-o e o adestrandoo em função de um espaço e tempo fincados em paradigmas positivistas, produtivistas e ascéticos, organizadores do sistema social da modernidade (LUZ, 2000, p. 38).

Achamos necessário ressaltar que o educando responsável pelo grafismo se considera um homem negro, periférico e que escolheu a profissão docente por compreender que a Educação pode modificar a realidade do seu bairro e de outras 
territorialidades. Com isso, se afastar dos elementos lúdicos das comunalidades afro-brasileiras obedece, também, às prerrogativas do sistema capitalista, da sociedade com forte viés ocidental e ao fazer acadêmico que exige, em diversos momentos, corporeidades engessadas e dispostas a acatar dos dogmas positivistas.

Os diálogos criaram outras vias de conhecimentos e verifiquei que a partir daqueles encontros as identidades de muitos dos educandos e educandas passaram por ressignificações intersubjetivas. Nesse cenário, cheguei naquele espaço como um mero observador, sem pretensões de envolvimentos afetivos significativos, mas acabei descontruindo uma série de certezas sobre o papel do Estágio Docente para a profissionalização do professor.

\section{Possibilidades (in)conclusivas}

O estágio é um momento de problematizações ou como muitos autores afirmam é o momento de constatação da práxis, ou seja, atividade teórica e prática educacional, da transformação da realidade docente (Pimenta, 2011). Um encontro entre a teoria e a prática docente. De fato, é caracterizado pelo embate dos nossos embasamentos metodológicos com as questões reais da sala de aula.

Assim como a educação básica a Universidade é constituída pela multiculturalidade que pode proporcionar ao estagiário desde o primeiro contato perceber a relevância da diferença no trato com as questões pedagógicas, visto que nos deparamos as diversidades culturais, sexuais, de gênero, étnicas entre tantas outras que são responsáveis pela construção da academia.

No estágio, realizado durante cinco encontros, intentei articular a práxis, pois desde o início, com as observações e pela regência, percebi o confronto das bases teóricas com a prática na sala de aula. Agradeço a gentileza e sensibilidade do professor regente, não apenas por ter permitido a minha inserção, mas, sobretudo por ter sido extremamente generoso, compreensivo e humilde. Aproveito e parabenizo os educandos e as educandas pela dedicação e empenho nas atividades, bem como na construção do espírito coletivo.

O estágio e a minha proposta de intervenção reafirmaram as minhas concepções acerca da categoria Desenho. Garantiram um retorno de que a minha escolha teórica tem respaldo no campo educacional. Posso afirmar que o desenho apresenta simbologias que em muitos casos só podem ser interpretados pelos indivíduos que os projetam, vivenciam e os reproduzem. 
Portanto, realizar a construção desta produção textual tem a prerrogativa de voltar no tempo, acessar as minhas memórias, refletir sobre as ações pautadas na minha formação, ou seja, "quando não souberes para onde ir, olha para trás e saiba pelo ou menos de onde vens" (Provérbio Africano).

\section{Referências}

ALARCÃO, I. (Coord.). Formação reflexiva de professores: estratégias de supervisão. Porto: Porto Editora, 2005.

ARAÚJO, Miguel Almir Lima de. Os sentidos da sensibilidade: sua fruição no fenômeno do educar. Salvador: EDUFBA. 2008.

ARBACHE, R. B. Ana Paula. A identidade docente no contexto multicultural: implicações para o fazer pedagógico. Revista de educação CEAP, Salvador, no 30, p. 37-48, Set/ Nov 2000.

FREIRE, P. Professora sim, tia não. 9 ed. São Paulo, SP: Olho d'Água, 1998.

FERREIRA, Edson Dias. Desenho e Antropologia: influencias da cultura na produção autoral. In Anais: Graphica, 2005. Disponível em: < http://www.lematec.net.br/CDS/GRAPHICA05/artigos/edsonferreira.pdf >. Acesso em 24/07/2017.

FERREIRA, Edson Dias. Desenho, fotografia e cultura na era da informática. In Anais do VII International Conference on Graphics Engineering for Arts and Design. Curitiba: 2007. Disponível em: < http://www.exatas.ufpr.br/portal/docs degraf/artigos graphica/DESENHO,\%20FOT OGRAFIA\%20E\%20CULTURA.pdf >. Acesso em 30/06/2017.

GOMES, Luiz Vidal Negreiros. Desenhismo. Santa Maria: Universidade Federal de Santa Maria, 1996.

HALL, Stuart. A identidade cultural na pós-modernidade. Rio de Janeiro: DP\&A, 2006.

LUZ, Narcimária Correia do Patrocínio. Abebe: A Criação de Novos Valores Na Educação. Salvador/Bahia: SECNEB, 2000. 
MACEDO, Roberto Sidnei. Etnopesquisa crítica, Etnopesquisa-formação. Brasília, DF: Liber livro, 2006.

MIRANDA, Eduardo Oliveira. "O negro do pomba quando sai da rua nova, ele traz na cinta uma cobra coral": os desenhos dos corpos-territórios evidenciados pelo afoxé pomba de malê. Dissertação de Mestrado (Programa de Pós-graduação em Desenho, Cultura e Interatividade - PPGDCI) - Universidade Estadual de Feira de Santana - UEFS: Feira de Santana, 2014. 182 f.

MORIN, Edgar. 0 método 3: O conhecimento do conhecimento. 2 ed. Portugal: Publicações Europa-America, 1999.

MORIN, Edgar. Um Animal Dotado de Desrazão, In: O enigma do homem. Rio de Janeiro: Zahar editores, 1975.

MOURA, Marinaide Ramos. O simbólico em Cassirer. Ideação, N. 5, p. 75-85, jan./jun. 2000.

MUNANGA, Kabenguele. Rediscutindo a mestiçagem no Brasil. Belo Horizonte: Autêntica, 2008.

PIMENTA, S.G.; LIMA, M.S.L. Estágio e docência. São Paulo, Cortez Editora, 2011.

i Graduado em Licenciatura em Geografia pela Universidade Estadual de Feira de Santana UEFS. Graduado em Peadgogia - FAC. Discente do Doutorado em Educação na Universidade Federal da Bahia. Professor da Faculdade de Educação - FACED/UFBA. Mestrado em Desenho, Cultura e Interatividade - UEFS. eduardomiranda48@gmail.com

Como citar esse artigo:

MIRANDA, Eduardo Oliveira. Estágio Docente, Desenho e Símbolo: tríade para investigar e compreender corporeidades afro-brasileiras. Revista Digital do LAV, Santa Maria: UFSM, v. 10, n. 3, p. 127-142, set./dez. 2017.

Recebido em: 08 novembro 2017

Aprovado em: 11 dezembro 2017

Revista Digital do LAV - Santa Maria - vol. 10, n. 3, p. $127-142$ - set./dez. 2017 ISSN 1983 - 7348 http://dx.doi.org/10.5902/1983734828971 